
\title{
3 Research Square \\ The effect of the COVID-19 outbreak on children's behavior and parents' mental health in China: A research study
}

\section{Ruibei Bai}

Health center of the children, Xi'an Fourth Hospital

Zhaohui Wang ( $\nabla$ 745024118@qq.com )

Health center of the children, Xi'an Fourth Hospital

Jing Liang

Health center of the children, Xi'an Fourth Hospital

Jing Qi

Health center of the children, Xi'an Fourth Hospital

Xi He

Health center of the children, Xi'an Fourth Hospital

\section{Research Article}

Keywords: COVID-19, outbreak, children' behavior, parent' mental health, China Introduction

Posted Date: April 16th, 2020

DOI: https://doi.org/10.21203/rs.3.rs-22686/v1

License: (c) (1) This work is licensed under a Creative Commons Attribution 4.0 International License. Read Full License 


\section{Abstract}

\section{Objectives}

The purpose of this study was to explore the impact of the COVID-19 outbreak on children's behavior and their parents' mental health in China.

\section{Methods}

A total of 30861 children's parents were selected from throughout China to complete the self-made Child behavior Questionnaire and Child Parents Mental Health Questionnaire.

\section{Results}

The results showed that there were significant differences in children's behavior scores in variables such as age, whether or not an only child and place of residence; There were significant differences in physical, emotional and cognitive scores of parents in variables such as gender, age, education, occupation, place of residence, whether there are medical staff in family, the relationship with children, and children's age. The correlation analysis showed that children's behavior and parents' physical, emotion and cognition were significantly correlated with epidemic-related factors. The stepwise multiple linear regression analysis showed that epidemic-related factors can significantly predict children's behavior and parents' physical, emotion, and cognition.

\section{Conclusions}

These results can provide theoretical basis for the behavior management of children at home and the psychological adjustment of parents during the epidemic.

\section{Introduction}

Since the end of December 2019, the COVID-19caused by severe acute respiratory syndrome coronavirus infection has begun to spread from Wuhan, China, and gradually spread throughout the country. This incident aroused the attention of countries around the world, and was listed as a public health emergency of international concern by the World Health Organization (WHO) on February 11, 2020. In early March 2020, COVID-19 began to spread worldwide. The COVID-19 not only seriously threatens the physical and mental health of patients and their family members, but also lead to mental health problems in the public (Yi, Wang, Jiang, Zheng, and Wu, 2010). In such times, it is very important to understand the psychological and behavioral health status of the public and take intervention measures. As a special group, children's behavior and their parents' mental health during the epidemic need to be taken seriously.

\section{The impact of the COVID-19 outbreak on children}


Children have lower immunity and weaker awareness of self-prevention, and are among the focus groups during the peak of the epidemic (Fang and Luo 2020). During the epidemic, it is important to focus on changes in children's psychological behavior. Previous studies have shown that children's psychological behavior is easily affected by family and social environment (Gao, Xing, and Zhao, 2016). Affected by the epidemic, children cannot return to school on time and cannot communicate face-to-face with peers. Children tend to react negatively to such long-term negative events (Buchanan, 2017), such as reduced learning time, increased use of electronic products, and changes in sleep patterns. In addition, parents' psychological stress during the epidemic will also affect children's behavior ( $\mathrm{Li}$, Zhu, and $\mathrm{He}, 2016)$. Children's bad behavior can affect their overall development (Frank, 2015), so it is important to investigate the impact of the epidemic on children's behavior.

\section{The impact of the COVID-19 outbreak on children's parents}

At the peak of the epidemic, children's parents often have a series of negative emotions, including anxiety, depression and hypochondriasis (Du, Yang, Cai, Zhang, and Bai, 2018; David, 2015). The main manifestations are constant vigilance, excessive attention to the progress of the incident, excessive attention to the health of themselves and their families, and suspicion of their infection without a basis (Kaseva, Dobewall, Yang, Laura, and Tammelin, 2019). At the same time, cannot go out for a long time at home, easy to appear dizziness, muscle soreness and other physical symptoms (Marylene, Christina, Margaret-Anne, Donn, and Jean, 2018). In addition, parents' excessive attention to children may have adverse effects on parents' concentration (Buder et al., 2016). Therefore, it is necessary to investigate the impact of the epidemic on the physical, emotion and cognition of children's parents.

\section{The current study}

The current study compiled a questionnaire to investigate the parents' cognition of the epidemic, and explore the children's behaviors and parents' mental health status in different demographic variables, as well as the epidemic-related factors affecting children's behaviors and parents' mental health status. Based on the characteristics of epidemic peaks, the study conducted preliminary psychological and behavioral health assessment and provided a basis for timely psychological intervention and reduction of public psychological problems.

\section{Method}

\section{Participants}

A total of 30861 children under the age of 18 and their parents were selected from the all provinces, autonomous regions and municipalities directly under the central government in China as respondents through the online platform, including 15800 boys (51.2\%), 15061 girls (48.8\%), 7373 male parents $(23.9 \%)$ and 23488 female parents $(76.1 \%)$. All respondents provided informed consent and volunteered to participate in this study. 


\section{Procedure}

The study was based on the previous research scales used in relevant literature and compiled a questionnaire suitable for the special period of the epidemic. Through the preliminary small-scale interviews, designed items that meet the research goals, and invited three experts in mental health, public health, and statistics to test the content validity of items. A preliminary survey of 130 respondents was conducted from February 12 to 13,2020 , and further improved the questionnaire items. The final questionnaire used in this study has a total of 60 items, and the respondents were formally surveyed during the peak period of the COVID-19 epidemic from February 14 to 20, 2020.

\section{Measures}

According to the purpose of the study, the "mental health status questionnaire" for children and their parents in the epidemic period of COVID-19 was compiled. It consists of three parts:

General Situation Questionnaire The questionnaire includes the parent section and the child section. There are 20 items in the parent section, including the demographic characteristics, the cognition and attitude towards COVID-19. And there are 15 items in the children section, including the demographic characteristics, and the impact of the epidemic on the children.

Child Behavior Questionnaire The questionnaire is mainly composed of children's recent behaviors such as time spent on electronic products, sleep condition, work and rest time, how much activity, change in concentration and temper. It consists of 6 items, each item has to be scored on a 3-point scale $(-1=$ better, $0=$ no change, $1=$ worse). The higher the score, the worse the children' behavior. In current study, the Cronbach's a was 0.728 .

Child Parents Mental Health Questionnaire The questionnaire includes three subscales of physical, emotion and cognition, which are composed of 5 items, 9 items, and 5 items, respectively. Each items has to be scored on a 3-point scale ( 0 = never, $1=$ occasionally, $2=0$ ften). The higher the score, the worse the situation. In current study, the Cronbach's a were $0.771,0.863,0.850$, respectively.

\section{Data analysis}

The statistical analysis was performed using SPSS 25.0 software package. The count data is expressed by the number of cases (n) and percentage (\%), and the measurement data is expressed by P5O (P25 P75). Descriptive analysis was performed on the proportion of the demographic characteristics of the surveyed respondents. The non-parametric analysis Kruskal -Wallis $H$ test was used to compare two independent groups. Spearman correlation analysis and stepwise multiple linear regression analysis were used to analyze the influencing factors of children's behavior and parents' mental health status. $P<0.05$ is considered statistically significant.

\section{Results}


The general situations of children and parents during the COVID-19 epidemic

A total of 30861 questionnaires were collected in this study. The general information of the respondents in the epidemic period is shown in Table 1.

Table 1 The general situations of children and parents during the COVID-19 epidemic 


\begin{tabular}{|c|c|c|c|}
\hline Questions & Option & $\mathrm{n}$ & $\%$ \\
\hline \multirow[t]{3}{*}{ Knowledge of theCOVID-19 } & 1.Do not know much & 2474 & 8.0 \\
\hline & 2.Know more & 22117 & 71.7 \\
\hline & 3.Know a lot about & 6270 & 20.3 \\
\hline \multirow[t]{2}{*}{ Whether familiar people are suspected of infection } & 1.Yes & 347 & 1.1 \\
\hline & 2.No & 30514 & 98.9 \\
\hline \multirow[t]{3}{*}{ The impact of the epidemic on household income } & 1.No effect & 6987 & 22.6 \\
\hline & 2.Less affected & 13767 & 44.6 \\
\hline & 3.More affected & 10107 & 32.8 \\
\hline \multirow[t]{3}{*}{ Worried about the outbreak being out of control } & 1.Never & 13028 & 42.2 \\
\hline & 2.Occasionally & 13728 & 44.5 \\
\hline & 3.Often & 4105 & 13.3 \\
\hline \multirow[t]{2}{*}{ Whether there are medical staff in the family } & 1.With & 3954 & 12.8 \\
\hline & 2.Without & 26907 & 87.2 \\
\hline \multirow[t]{2}{*}{ Recent changes in sleep } & 1.No change & 22800 & 73.9 \\
\hline & 2.Changes in sleep patterns & 8061 & 26.1 \\
\hline \multirow[t]{3}{*}{ Self-assess physical health } & 1.Good & 19636 & 63.6 \\
\hline & 2.General & 10976 & 35.6 \\
\hline & 3.Not good & 249 & 0.8 \\
\hline \multirow[t]{3}{*}{ Self-assess mental health } & 1.Good & 21913 & 71.0 \\
\hline & 2.General & 8710 & 28.2 \\
\hline & 3.Not good & 238 & 0.8 \\
\hline \multirow[t]{2}{*}{ Impact of the epidemic on children's sleep } & 1.Have effect & 8177 & 26.3 \\
\hline & 2.No effect & 22744 & 73.7 \\
\hline \multirow[t]{2}{*}{ Impact of the epidemic on children's emotion } & 1.Have effect & 3932 & 12.7 \\
\hline & 2.No effect & 26929 & 87.3 \\
\hline \multirow[t]{3}{*}{ Worried about child's illness } & 1.Never & 6441 & 20.9 \\
\hline & 2.Occasionally & 20500 & 66.4 \\
\hline & 3.Often & 3920 & 12.7 \\
\hline \multirow[t]{3}{*}{ Worried about child being infected } & 1.Never & 8870 & 28.7 \\
\hline & 2.Occasionally & 17290 & 56.1 \\
\hline & 3.Often & 4701 & 15.2 \\
\hline \multirow[t]{3}{*}{ Worried about when your child will be vaccinated } & 1.Never & 15714 & 50.9 \\
\hline & 2.Occasionally & 12739 & 41.3 \\
\hline & 3.Often & 2408 & 7.8 \\
\hline \multirow[t]{5}{*}{ Regions by number of confirmed cases } & $1 . \geq 10000$ & 104 & 0.3 \\
\hline & $2.1000 \sim 9999$ & 380 & 1.2 \\
\hline & $3.500 \sim 999$ & 487 & 1.6 \\
\hline & $4.100 \sim 499$ & 28045 & 90.9 \\
\hline & $5 .<100$ & 1845 & 6.0 \\
\hline
\end{tabular}




\section{The behavioral status of children in different demographic variables}

There was no significant gender difference in children's behavior scores $(H=0.582, P>0.05)$. There were significant age differences in children's behavior scores $(H=298.435, P<0.001)$. Statistical difference was further analyzed by Post hoc analysis using Bonferroni method. Other age groups had higher behavioral scores than children under 3 years old, and children 4-6 years old had higher behavioral scores than children 7-12 years old and older. There was a significant difference in behavior scores between the only child and the non-only child $(H=32.350, P<0.001)$. There were significant differences in behavior scores among children in different places of residence $(H=176.506, P<0.001)$. Pairwise comparisons showed that children in cities had higher behavioral scores than children in towns and rural areas, and children in towns had higher scores than children in rural areas. See Table 2.

Table 2 Differences in scores in children's behaviors among different demographic variables

\begin{tabular}{|c|c|c|}
\hline Variables & Groups & Behavioral status of children \\
\hline \multirow{4}{*}{ Gender } & Male & $1.00 \square 0.00 \square 2.00 \square$ \\
\hline & Female & $1.00 \square 0.00 \square 2.00 \square$ \\
\hline & $H$ & 0.582 \\
\hline & $P$ & 0.445 \\
\hline \multirow[t]{6}{*}{ Age } & Under 3 years & $0.00 \square 0.00 \square 1.00 \square$ \\
\hline & 4-6 years & $1.00 \square 0.00 \square 2.00 \square$ \\
\hline & 7-12 years & $1.00 \square 0.00 \square 2.00 \square$ \\
\hline & 12 years and older & $1.00 \square 0.00 \square 2.00 \square$ \\
\hline & $H$ & 298.435 \\
\hline & $P$ & $\square 0.001$ \\
\hline \multirow[t]{4}{*}{ Whether or not an only child } & Yes & $1.00 \square 0.00 \square 2.00 \square$ \\
\hline & No & $1.00 \square 0.00 \square 2.00 \square$ \\
\hline & $H$ & 32.350 \\
\hline & $P$ & $\square 0.001$ \\
\hline \multirow[t]{5}{*}{ Place of residence } & City & $1.00 \square 0.00 \square 2.00 \square$ \\
\hline & Town & $1.00 \square 0.00 \square 2.00 \square$ \\
\hline & Rural area & $1.00 \square 0.00 \square 2.00 \square$ \\
\hline & $H$ & 176.506 \\
\hline & $P$ & $\square 0.001$ \\
\hline
\end{tabular}

\section{Mental health status of children's parents in different demographic variables}

The results from Table 3 showed that there were no significant differences in parents' physical, emotional, and cognitive scores in children's gender variables $(P>0.05)$. There were significant differences in physical, emotional and cognitive scores in variables such as parents' gender, parents' age, parents' education, parents' occupation, place of residence, whether there are medical staff in family, the relationship with children, and children's age $(P<0.001)$. Statistical difference was further analyzed 
by Post hoc analysis using Bonferroni method. Women's physical, emotional, and cognitive scores were significantly higher than men's; Physical and cognitive scores were the lowest under 30 years, and emotional scores were the lowest over 50 years; In terms of parents' education, the higher the education, the higher the physical, emotional, and cognitive scores. Medical staffs had the highest physical, emotional and cognitive scores; The physical, emotional, and cognitive scores in rural areas were significantly lower than those in cities and towns; In whether there are medical staffs in the family, the physical, emotional and cognitive scores of the medical staff in the family were significantly higher than those of the parents without medical staff in the family; In terms of relationships with children, fathers had lower physical and cognitive scores, and mothers had higher emotional scores; Parents of children under 3 years of age had significantly higher physical, emotional and cognitive scores than parents of children of other ages.

Table 3 Differences in scores in mental health status of children's parents among different demographic variables 


\begin{tabular}{|c|c|c|c|c|}
\hline & $\mathrm{n}$ & Physical & Emotion & Cognition \\
\hline \multicolumn{5}{|l|}{ Gender } \\
\hline Male & 7373 & $0.00 \square 0.00 \sim 1.00 \square$ & $1.00 \square 0.00 \sim 4.00 \square$ & $1.00 \square 0.00 \sim 3.00 \square$ \\
\hline Female & 23488 & $0.00 \square 0.00 \sim 1.00 \square$ & $0.00 \square 0.00 \sim 1.00 \square$ & $2.00 \square 0.00 \sim 4.00 \square$ \\
\hline$H$ & & 54.54 & 443.89 & 477.14 \\
\hline$P$ & & $\square 0.001$ & $\square 0.001$ & $\square 0.001$ \\
\hline \multicolumn{5}{|l|}{ Age } \\
\hline Under 30 years & 7218 & $0.00 \square 0.00 \sim 1.00 \square$ & $2.00 \square 0.00 \sim 5.00 \square$ & $2.00 \square 0.00 \sim 4.00 \square$ \\
\hline $30 \sim 40$ years & 20193 & $0.00 \square 0.00 \sim 1.00 \square$ & $2.00 \square 0.00 \sim 5.00 \square$ & $2.00 \square 0.00 \sim 4.00 \square$ \\
\hline $40 \sim 50$ years & 2683 & $0.00 \square 0.00 \sim 1.00 \square$ & $2.00 \square 0.00 \sim 5.00 \square$ & $2.00 \square 0.00 \sim 4.00 \square$ \\
\hline 50 years and older & 767 & $0.00 \square 0.00 \sim 1.00 \square$ & $1.00 \square 0.00 \sim 4.00 \square$ & $2.00 \square 0.00 \sim 4.00 \square$ \\
\hline$H$ & & 108.74 & 51.44 & 37.28 \\
\hline$P$ & & $\square 0.001$ & $\square 0.001$ & $\square 0.001$ \\
\hline \multicolumn{5}{|l|}{ Education } \\
\hline high school and below & 14207 & $0.00 \square 0.00 \sim 1.00 \square$ & $2.00 \square 0.00 \sim 5.00 \square$ & $2.00 \square 0.00 \sim 4.00 \square$ \\
\hline College & 8795 & $0.00 \square 0.00 \sim 1.00 \square$ & $2.00 \square 0.00 \sim 5.00 \square$ & $2.00 \square 0.00 \sim 4.00 \square$ \\
\hline Undergraduate & 7131 & $0.00 \square 0.00 \sim 1.00 \square$ & $3.00 \square 0.00 \sim 6.00 \square$ & $2.00 \square 0.00 \sim 4.00 \square$ \\
\hline Master and above & 728 & $1.00 \square 0.00 \sim 2.00 \square$ & $4.00 \square 1.00 \sim 7.00 \square$ & $2.00 \square 0.00 \sim 5.00 \square$ \\
\hline$H$ & & 699.21 & 171.18 & 119.93 \\
\hline$P$ & & $\square 0.001$ & $\square 0.001$ & $\square 0.001$ \\
\hline \multicolumn{5}{|l|}{ Occupation } \\
\hline Medical staffs & 2350 & $1.00 \square 0.00 \sim 2.00 \square$ & $4.00 \square 1.00 \sim 7.00 \square$ & $3.00 \square 1.00 \sim 5.00 \square$ \\
\hline Cadres & 2210 & $0.00 \square 0.00 \sim 1.00 \square$ & $2.00 \square 0.00 \sim 5.00 \square$ & $2.00 \square 0.00 \sim 5.00 \square$ \\
\hline Farmers & 5456 & $0.00 \square 0.00 \sim 0.00 \square$ & $2.00 \square 0.00 \sim 5.00 \square$ & $2.00 \square 0.00 \sim 5.00 \square$ \\
\hline Workers & 3463 & $0.00 \square 0.00 \sim 1.00 \square$ & $2.00 \square 0.00 \sim 5.00 \square$ & $2.00 \square 0.00 \sim 5.00 \square$ \\
\hline Other & 17382 & $0.00 \square 0.00 \sim 1.00 \square$ & $3.00 \square 0.00 \sim 5.00 \square$ & $2.00 \square 0.00 \sim 5.00 \square$ \\
\hline$H$ & & 1004.05 & 397.63 & 227.66 \\
\hline$P$ & & $\square 0.001$ & $\square 0.001$ & $\square 0.001$ \\
\hline \multicolumn{5}{|l|}{ Place of residence } \\
\hline City & 16375 & $0.00 \square 0.00 \sim 1.00 \square$ & $3.00 \square 0.00 \sim 6.00 \square$ & $2.00 \square 0.00 \sim 4.00 \square$ \\
\hline Town & 5378 & $0.00 \square 0.00 \sim 1.00 \square$ & $2.00 \square 0.00 \sim 5.00 \square$ & $2.00 \square 0.00 \sim 4.00 \square$ \\
\hline Rural area & 9108 & $0.00 \square 0.00 \sim 0.00 \square$ & $2.00 \square 0.00 \sim 5.00 \square$ & $2.00 \square 0.00 \sim 4.00 \square$ \\
\hline$H$ & & 440.15 & 199.27 & 126.11 \\
\hline$P$ & & $\square 0.001$ & $\square 0.001$ & $\square 0.001$ \\
\hline
\end{tabular}

Whether there are medical staff in the family

$\begin{array}{lcccc}\text { With } & 3954 & 0.00 \square 0.00 \sim 1.00 \square & 3.00 \square 0.00 \sim 6.00 \square & 2.00 \square 0.00 \sim 4.00 \square \\ \text { Without } & 26907 & 0.00 \square 0.00 \sim 1.00 \square & 2.00 \square 0.00 \sim 5.00 \square & 2.00 \square 0.00 \sim 4.00 \square \\ H & & 279.34 & 55.91 & 42.89 \\ P & \square 0.001 & \square 0.001 & \square 0.001\end{array}$

Relationship with children

$\begin{array}{lrrrr}\text { Mother } & 23262 & 0.00 \square 0.00 \sim 1.00 \square & 3.00 \square 0.00 \sim 6.00 \square & 2.00 \square 0.00 \sim 4.00 \square \\ \text { Father } & 6547 & 0.00 \square 0.00 \sim 1.00 \square & 1.00 \square 0.00 \sim 4.00 \square & 1.00 \square 0.00 \sim 3.00 \square\end{array}$




\begin{tabular}{lcccc} 
Grandmother & 509 & $0.00 \square 0.00 \sim 1.00 \square$ & $1.00 \square 0.00 \sim 5.00 \square$ & $2.00 \square 0.00 \sim 4.00 \square$ \\
Grandfather & 195 & $0.00 \square 0.00 \sim 1.00 \square$ & $1.00 \square 0.00 \sim 4.00 \square$ & $2.00 \square 0.00 \sim 4.00 \square$ \\
Other & 348 & $0.00 \square 0.00 \sim 1.00 \square$ & $2.00 \square 0.00 \sim 5.00 \square$ & $2.00 \square 0.00 \sim 4.00 \square$ \\
$H$ & & 49.53 & 508.62 & 506.46 \\
$P$ & & $\square 0.001$ & $\square 0.001$ & $\square 0.001$ \\
Children's gender & & & & \\
Male & 15800 & $0.00 \square 0.00 \sim 1.00 \square$ & $2.00 \square 0.00 \sim 5.00 \square$ & $2.00 \square 0.00 \sim 4.00 \square$ \\
Female & 15061 & $0.00 \square 0.00 \sim 1.00 \square$ & $2.00 \square 0.00 \sim 5.00 \square$ & $2.00 \square 0.00 \sim 4.00 \square$ \\
$H$ & & 3.354 & 0.127 & 0.004 \\
$P$ & & 0.067 & 0.722 & 0.952 \\
Children's age & & & & \\
Under 3 years & 1201 & $1.00 \square 0.00 \sim 2.00 \square$ & $4.00 \square 1.00 \sim 7.00 \square$ & $3.00 \square 0.00 \sim 5.00 \square$ \\
$3 \sim 6$ years & 20597 & $0.00 \square 0.00 \sim 1.00 \square$ & $2.00 \square 0.00 \sim 5.00 \square$ & $2.00 \square 0.00 \sim 4.00 \square$ \\
$6 \sim 12$ years & 5210 & $0.00 \square 0.00 \sim 1.00 \square$ & $3.00 \square 0.00 \sim 6.00 \square$ & $2.00 \square 0.00 \sim 4.00 \square$ \\
12 years and older & 3853 & $0.00 \square 0.00 \sim 1.00 \square$ & $2.00 \square 0.00 \sim 5.00 \square$ & $2.00 \square 0.00 \sim 4.00 \square$ \\
$H$ & & 364.44 & 182.24 & 121.76 \\
$P$ & & $\square 0.001$ & $\square 0.001$ & $\square 0.001$ \\
\hline
\end{tabular}

\section{The relationship between epidemic-related factors, children's behavior and parents' mental health status}

The correlation analysis results in Table 4 showed that all epidemic-related factors were significantly related to children's behavior, parents' physical, parents' emotion, and parents' cognition $(P<0.05)$.

Table 4 The relationship between epidemic-related factors, children's behavior and parents' mental health status

\begin{tabular}{cccccccccccc}
\hline & 1 & 2 & 3 & 4 & 5 & 6 & 7 & 8 & 9 & 10 & 11 \\
\hline 1 & 1 & - & - & - & - & - & - & - & - & - & - \\
2 & $-0.016^{* *}$ & 1 & - & - & - & - & - & - & - & - & - \\
3 & $-0.062^{* *}$ & $0.016^{* *}$ & 1 & - & - & - & - & - & - & - & - \\
4 & $-0.067^{* *}$ & -0.004 & $0.189^{* *}$ & 1 & - & - & - & - & - & - & - \\
5 & $-0.095^{* *}$ & $0.074^{* *}$ & $0.077^{* *}$ & $0.034^{* *}$ & 1 & - & - & - & - & - & - \\
6 & $-0.015^{* *}$ & $-0.015^{* *}$ & $0.064^{* *}$ & $0.054^{* *}$ & $-0.017^{* *}$ & 1 & - & - & - & - & - \\
7 & $-0.079^{* *}$ & -0.007 & $0.234^{* *}$ & $0.562^{* *}$ & $0.025^{* *}$ & $0.081^{* *}$ & 1 & - & - & - & - \\
8 & $-0.073^{* *}$ & $-0.014^{*}$ & $0.173^{* *}$ & $0.130^{* *}$ & $-0.016^{* *}$ & $0.075^{* *}$ & $0.175^{* *}$ & 1 & - & - & - \\
9 & $-0.059^{* *}$ & $-0.095^{* *}$ & $0.051^{* *}$ & $0.106^{* *}$ & $-0.104^{* *}$ & $0.168^{* *}$ & $0.189^{* *}$ & $0.177^{* *}$ & 1 & - & - \\
10 & $-0.082^{* *}$ & $-0.049^{* *}$ & $0.198^{* *}$ & $0.303^{* *}$ & $-0.047^{* *}$ & $0.194^{* *}$ & $0.386^{* *}$ & $0.300^{* *}$ & $0.456^{* *}$ & 1 & - \\
11 & $-0.112^{* *}$ & $-0.036^{* *}$ & $0.151^{* *}$ & $0.207^{* *}$ & $-0.040^{* *}$ & $0.142^{* *}$ & $0.332^{* *}$ & $0.252^{* *}$ & $0.366^{* *}$ & $0.573^{* *}$ & 1 \\
\hline
\end{tabular}

Note: $1=$ Knowledge of the COVID-19, 2 = Whether familiar people are suspected of infection, $3=$ The impact of the epidemic on household income, $4=$ Worried about the outbreak being out of control, $5=$ Whether there are medical staff in the family, $6=$ Recent changes in sleep, $7=$ Parents ' worries about their 
children, $8=$ children's behavior, $9=$ parents' physical, $10=$ parents' emotion, $11=$ parents' cognition. ${ }^{*} p<$ $0.05 \rrbracket^{\star \star} p<0.01 \rrbracket^{\star \star \star} p<0.001$.

\section{The effect of epidemic-related factors on children's behavior and parents' mental health status}

The stepwise multiple linear regression analysis was used to examine the predictive effects of epidemicrelated factors on children's behavior and parents' mental health status. Children's behavior, parents' physical, parents' emotion and parents' cognition were taken as the dependent variables respectively, and 7 epidemic-related factors were gradually included into the regression equation as the independent variables to test the predictive effect.

Table 5 Regression analysis of epidemic-related factors affecting children's behavior and parents' mental health status

\begin{tabular}{|c|c|c|c|c|c|c|c|c|c|}
\hline $\begin{array}{c}\text { Dependent } \\
\text { variable }\end{array}$ & Predictor variable & $B$ & $S E$ & $\beta$ & $t$ & $p$ & $R$ & $\Delta R^{2}$ & $F$ \\
\hline \multirow[t]{8}{*}{ children's behavior } & & & & & & & 0.239 & 0.057 & $266.338^{* * *}$ \\
\hline & 7 & 0.085 & 0.005 & 0.116 & 17.063 & $<0.001$ & & & \\
\hline & 3 & 0.324 & 0.014 & 0.136 & 23.715 & $<0.001$ & & & \\
\hline & 6 & 0.082 & 0.009 & 0.053 & 9.620 & $<0.001$ & & & \\
\hline & 1 & -0.189 & 0.019 & -0.056 & -9.986 & $<0.001$ & & & \\
\hline & 5 & -0.181 & 0.029 & -0.034 & -6.150 & $<0.001$ & & & \\
\hline & 4 & 0.087 & 0.017 & 0.034 & 5.068 & $<0.001$ & & & \\
\hline & 2 & -0.212 & 0.092 & -0.013 & -2.295 & 0.022 & & & \\
\hline \multirow[t]{6}{*}{ parents' physical } & & & & & & & 0.283 & 0.080 & $538.706^{* * *}$ \\
\hline & 7 & 0.085 & 0.003 & 0.175 & 31.793 & $<0.001$ & & & \\
\hline & 6 & 0.152 & 0.006 & 0.150 & 27.337 & $<0.001$ & & & \\
\hline & 5 & -0.363 & 0.019 & -0.105 & -19.003 & $<0.001$ & & & \\
\hline & 2 & -0.933 & 0.060 & -0.085 & -15.485 & $<0.001$ & & & \\
\hline & 1 & -0.122 & 0.012 & -0.054 & -9.888 & $<0.001$ & & & \\
\hline \multirow[t]{8}{*}{ parents' emotion } & & & & & & & 0.452 & 0.204 & $1129.894^{* * *}$ \\
\hline & 7 & 0.377 & 0.008 & 0.282 & 45.277 & $<0.001$ & & & \\
\hline & 6 & 0.436 & 0.014 & 0.156 & 30.634 & $<0.001$ & & & \\
\hline & 3 & 0.443 & 0.023 & 0.102 & 19.483 & $<0.001$ & & & \\
\hline & 4 & 0.536 & 0.029 & 0.115 & 18.739 & $<0.001$ & & & \\
\hline & 5 & -0.622 & 0.049 & -0.065 & -12.723 & $<0.001$ & & & \\
\hline & 1 & -0.308 & 0.032 & -0.050 & -9.791 & $<0.001$ & & & \\
\hline & 2 & -1.268 & 0.154 & -0.042 & -8.238 & $<0.001$ & & & \\
\hline \multirow[t]{8}{*}{ parents' cognition } & & & & & & & 0.374 & 0.140 & $718.510^{* * *}$ \\
\hline & 7 & 0.253 & 0.006 & 0.289 & 44.623 & $<0.001$ & & & \\
\hline & 6 & 0.201 & 0.010 & 0.110 & 20.730 & $<0.001$ & & & \\
\hline & 1 & -0.354 & 0.022 & -0.088 & -16.466 & $<0.001$ & & & \\
\hline & 3 & 0.204 & 0.016 & 0.072 & 13.182 & $<0.001$ & & & \\
\hline & 5 & -0.364 & 0.033 & -0.058 & -10.921 & $<0.001$ & & & \\
\hline & 2 & -0.612 & 0.105 & -0.031 & -5.829 & $<0.001$ & & & \\
\hline & 4 & 0.063 & 0.020 & 0.021 & 3.247 & 0.001 & & & \\
\hline
\end{tabular}

Note: $1=$ Knowledge of the COVID-19, 2 = Whether familiar people are suspected of infection, $3=$ The impact of the epidemic on household income, $4=$ Worried about the outbreak being out of control, $5=$ 
Whether there are medical staff in the family, $6=$ Recent changes in sleep, $7=$ Parents' worries about their children. ${ }^{*} p<0.05 \rrbracket^{\star \star} p<0.01 \rrbracket^{\star \star *} p<0.001$.

With children's behavior taking as the dependent variable, all 7 epidemic-related factors accounted for $5.7 \%$ of the variation. With parents' physical taking as the dependent variable, 5 epidemic-related factors accounted for $8.0 \%$ of the variation. With parents' emotion taking as the dependent variable, all 7 epidemic-related factors accounted for $20.4 \%$ of the variation. With parents' cognition taking as the dependent variable, all 7 epidemic-related factors accounted for $14.0 \%$ of the variation.

\section{Discussion}

\section{The cognition and attitude towards COVID-19 of children' parents}

According to the survey, the parents' understanding rate of the COVID-19 reached $92 \%$. This result showed that the Novel Coronavirus Pneumonia Prevention and Control Program published by the China's National Health Commission have played a widespread role. Children's parents can timely understand the epidemic-related information, and do a good job in personal protection, consciously comply with the public health regulations, so that the outbreak is effectively controlled. The economic income of $77 \%$ of

households was affected by the epidemic. For the prevention and control of the epidemic, enterprises and factories delayed the resumption of work. Although the economic income was reduced, it did not affect the quality of life. Additionally, the survey results showed that most parents worry about the physical condition of the children during the epidemic, which will increase parents' anxiety (Buder et al., 2016). In general, the epidemic has affected the living habits and psychological conditions of children and their parents to a certain extent.

\section{Children's behaviors and parents' mental health status among different demographic variables}

School-age children were more likely to have bad behavior during the epidemic. Previous study have indicated that school-age children have a certain ability to judge crisis and can use electronic products proficiently, and are susceptible to the negative information of the media network (White, 2017; Oppenheimer et al., 2016). Non-only children are more prone to bad behavior during the epidemic. Previous studies have shown that non-only children are more aware of the stress caused by the surrounding environment and prone to bad behavior than only children $(\mathrm{Hu}$, Ren, and Yang, 2019; Li, et al., 2015). Children in cities had more bad behaviors. The epidemic of cities is relatively serious, and parents' bad moods increase, threatening children even more, resulting in bad behavior. Therefore, the school-age children of cities who are non-only children are the people who need to focus on during the epidemic.

Female parents had higher physical, emotional, and cognitive scores than male parents. Studies have shown that women are emotionally unstable and stressed out, which can worsen their physical condition (Julie, 2016). Women are sensitive to negative emotions and difficult to adjust (Agneta, Mariska, and 
Joost, 2018). And males' cognitive ability is not easily affected by the environment (Onyekuru, 2015). The 30-year-old and younger groups were lower than those of other age groups, indicating that younger parents have positive cognition of epidemic prevention and control (Grevenbrock, Groneck, Ludwig, and Zimper, 2018). The 50-year-old and above age groups had the lowest emotional score because older people have more stable emotions in the face of emergencies (Katharina, Nanna, Marguerite, Gregory, and lan, 2018). In terms of education, the higher the parents' education, the higher the mental health scores. It means that parents with higher education have deeper understanding of the epidemic information, which is more likely to cause psychological panic. Medical staff scored higher on mental health. During the epidemic, due to the influence of working hours and working environment, medical staffs are more likely to have tension and anxiety (Grill and Elizabeth, 2015). Parents living in cities scored higher on mental health. The reason is that people living in cities are more worried about the spread of the epidemic, which causes physical discomfort and psychological tension. Parents with medical staff in the family scored higher on mental health. These people are at higher risk of contracting the virus, which will increase psychological stress (Bray, Hourani, Williams, Lane, and Marsden, 2014). The scores of parents' mental health status of children of 3-year-old and younger were found to be higher. These children have a limited level of cognition, and lack proper understanding of the epidemic, so prevention awareness is weak (White, 2017). Parents of these children were more physically tired, more emotionally negative and more cognitively distracted (Barone and Lionetti, 2012).

\section{The predictive effects of epidemic-related factors on children's behavior and parents' mental health status}

The impact of the epidemic on household income and parents' worries about their children were more strongly correlated with children's behaviors. Previous studies have shown that family economic conditions have a regulating effect on children's behavior (Liu, Zhao, Gao, Han, and Huang, 2019). Other studies have shown that parents' high levels of worry will increase children's behavior problems (Nejra, Maria, and Kar, 2018). The impact of recent changes in sleep and parents' worries about their children were more strongly correlated with parents' physical. Irregular sleep pattern can increase the risk of organic illness (Selvamani, Arokiasamy, Chaudhary, and Himanshu, 2018). And excessive parental concerns about children can also increase the body burden (Buder et al., 2016). The impact of worried about the outbreak being out of control and parents' worries about their children were more strongly correlated with parents' emotion and cognition. False statements about the epidemic in online media will cause social panic and affect people's mental health, and the relevant departments should control the spread of rumors.

The regression analysis found that epidemic-related factors can predict children's behavior. Firstly, parents and children should learn about the knowledge about epidemic together and have correct cognition to the epidemic. Secondly, due to the impact of the epidemic, children spend long hours at home, resulting in increased use of electronic products and irregular sleep. Parents should increase parent-child interaction time, which can not only reduce the use time of electronic products, but also can reduce other behavioral problems (Haley, Alexie, and Ryan, 2016). In addition, parents should not only supervise their children's behavior and performance, but also respect their children's sense of identity and 
needs, and help their children improve their self-management ability (Wang, Zhang, Zhao, Zhang, and Jiang, 2020). The epidemic-related factors can also predict parents' physical, emotion and cognition. Firstly, parents should obtain real information through the official media. Secondly, parents can seek social support to reduce tension by calling a psychological aids hotline (Timothy and Karen, 2019). Thirdy, family members should provide emotional support to each other to reduce the psychological pressure (Taylor, Forsythebrown, Lincoln, and Chatters, 2017). Finally, psychological professionals should provide self-adjustment methods for the public online. In general, all sectors of society should strengthen the psychological counseling of different groups of people.

\section{Conclusion}

During the peak period of the COVID-19, the government and the community's publicity and education and prevention and control work played an important role, the people of the whole country can actively cooperate, speed up the control of the epidemic. There were significant differences in children's behavior and parents' mental health status among different demographic characteristics. These differences can be mitigated by epidemic control, psychological intervention, and self-direction. Epidemic-related factors significantly predicted children's behavior and parents' physical, emotional, and cognition. And from these factors, intervention strategies can be formulated. These survey results not only enrich the research field, but also provide theoretical basis for psychological counseling of children and their parents.

\section{Limitations}

The first limitation is that this study only investigated the psychological conditions of respondents during the peak period of the epidemic, and did not investigate it at the beginning of the epidemic and when the epidemic eased. We cannot understand the changes in their psychological conditions. Follow-up investigations will be continued in future work to make the research results more complete.

The second limitation is that there are only 6 items in the Child Behavior Questionnaire, which is not comprehensive enough. In the follow-up study, add items to the Child Behavior Questionnaire, such as children's eating habits, hygiene habits, learning habits, etc., to better understand the impact of the epidemic on children.

\section{Declarations}

\section{Ethical approval}

All procedures performed in studies involving human participants were in accordance with the ethical standards of the institutional research committee and with the 1964 Helsinki declaration and its later amendments or comparable ethical standards.

\section{Informed consent}


Informed consent was obtained from all individual participants included in the study. And we always observed the privacy rights of human subjects.

\section{Declarations of interest}

The authors declare that they have no conflict of interest.

\section{Submission declaration}

This article has not been published previously, and it is not under consideration for publication elsewhere.

\section{Funding sources}

This research was supported by Shannxi key research and development program (2018SF-081) and Xi'an Science and technology plan project (201805098YX6SF32(8)).

\section{Acknowledgements}

This research was supported by Shannxi key research and development program (2018SF-081) and Xi'an Science and technology plan project (201805098YX6SF32(8)).

\section{Submission declaration}

This article has not been published previously, and it is not under consideration for publication elsewhere.

\section{Ethical approval}

All procedures performed in studies involving human participants were in accordance with the ethical standards of the institutional research committee and with the 1964 Helsinki declaration and its later amendments or comparable ethical standards.

\section{Informed consent}

Informed consent was obtained from all individual participants included in the study. And we always observed the privacy rights of human subjects.

\section{References}

Agneta H. Fischer, Mariska E. Kret, Joost Broekens (2018) Gender differences in emotion perception and self-reported emotional intelligence: a test of the emotion sensitivity hypothesis. Plos One, 13(1), e0190712.

Barone, L. , Lionetti, F (2012) Attachment and emotional understanding: a study on late-adopted preschoolers and their parents. Child Care Health \& Development, 38(5), 690-696. 
Buchanan, H (2017) Coping Styles in Children. Dental Fear and Anxiety in Pediatric Patients.

Buder, K. , Werner, H. , Landolt, M. A. , Neuhaus, T. J. , Laube, G. F. , Spartà, Giuseppina (2016).Healthrelated quality of life and mental health in parents of children with hemolytic uremic syndrome. Pediatric Nephrology, 31(6), 923-932.

Bray, R. M. , Hourani, L. L. , Williams, J. , Lane, M. E. , Marsden, M. E. (2014) Stress and Mental Health. Understanding Military Workforce Productivity.

David W Harrison (2015) Positive and Negative Emotion. Brain Asymmetry and Neural Systems.

Du, Z. , Yang, Y. , Cai, Q. , Zhang, C. , Bai, Y. (2018) Modeling and inferring mobile phone users' negative emotion spreading in social networks. Future generation computer systems, 78(PT.3), 933-942.

Fang F., Luo X.(2020) Facing a major epidemic of 2019 novel coronavirus infection: pediatricians' thoughts. Chinese Journal of Pediatrics, 58(2), 81-85.

Frank Verhulst (2015) Commentary: physical health outcomes and health care have improved so much, so why is child mental health getting worse? or is it? a commentary on collishaw (2015). J Child Psychol Psychiatry, 56(3), 394-396.

Gao X, Xing S, Zhao J. (2016) Parental psychological control and the relationship with children's psychosocial functioning. Advances in Psychological Science.

Grevenbrock, N. , Groneck, M. , Ludwig, A. , Zimper, A. (2018) Cognition, optimism and the formation of age-dependent survival beliefs. Alexander zimper.

Grill, Elizabeth (2015) Role of the mental health professional in education and support of the medical staff. Fertility \& Sterility, 104(2), 271-276.

Haley Kranstuber Horstman, Alexie Hays, Ryan Maliski (2016) Parent-child interaction.

Hu X., Ren X., Yang J. (2019) From the Self-Construal Perspective to Analyse the Differences of Daily Psychological Stress Level Between Only Children and Non-Only Children. Journal of Southwest University(Natural Science Edition), 41(4).

Julie M. Barkmeier-Kraemer (2016) Are women more unstable than men? shaky topics. Acoustical Society of America Journal, 139(4), 2107-2107.

Kaseva, K. , Dobewall, H. , Yang, X. , Laura Pulkki-Raback, Tammelin, T. (2019) Physical activity, sleep, and symptoms of depression in adults-testing for mediation. Medicine \& Science in Sports \& Exercise, 51(6), 1.

Katharina Kircanski, Nanna Notthoff, Marguerite DeLiema, Gregory R. Samanez-Larkin, lan H. Gotlib (2018) Emotional arousal may increase susceptibility to fraud in older and younger adults. Psychol 
Aging, 33(2), 325-337.

Li Y., Zhu J., He T (2016) The relation between mother's emotion regulation and children's emotion understanding competence: the mediating role of maternal reactions to children's negative emotions. Journal of Psychological Science.

Li Y., Liu L., Lv Y., Xu L., Wang Y., Huntsinger, C. S. (2015) Mother-child and teacher-child relationships and their influences on Chinese only and non-only children's early social behaviors: The moderator role of urban-rural status. Children and Youth Services Review, 51, 108-116.

Liu Y., Zhao C., Gao Y., Han L., Huang X. (2019) Influencing factors of psychological and behavioral development of left-behind children under 3 years old in poor rural in China. Chinese Journal of Child Health Care, 27(9), 941-944.

Marylene Cloitre, Christina Khan, Margaret-Anne Mackintosh, Donn W. Garvert, Jean Saito (2018) Emotion regulation mediates the relationship between aces and physical and mental health. Psychological Trauma Theory Research Practice \& Policy.

National Health Commission of the People's Republic of China. New coronavirus pneumonia prevention and control program. Beijing, China: National Health Commission of the People's Republic of China, 2020.

Nejra Van Zalk, Maria Tillfors, Kari Trost (2018) Mothers' and fathers' worry and over-control: one step closer to understanding early adolescent social anxiety. Child Psychiatry \& Human Development, 49(6), 111.

Onyekuru, B. U. (2015) Field dependence-field independence cognitive style, gender, career choice and academic achievement of secondary school students in emohua local government area of rivers state. Journal of education \& practice, 6.

Oppenheimer, C. W., Ladouceur, C. D., Waller, J. M., Ryan, N. D., Allen, K. B., Sheeber, L., ... Silk, J. S (2016) Emotion socialization in anxious youth: Parenting buffers emotional reactivity to peer negative events. Journal of abnormal child psychology, 44(7), 1267-1278.

Selvamani, Y. , Arokiasamy, P. , Chaudhary, M. , Himanshu (2018) Association of sleep problems and sleep duration with self-rated health and grip strength among older adults in india and china: results from the study on global aging and adult health (sage). Journal of Public Health, 26(6), 697-707.

Taylor, R. J. , Forsythebrown, I. , Lincoln, K. D. , Chatters, L. M. (2017) Extended family support networks of caribbean black adults in the united states. J Fam Issues, 38(4), 522-546.

Timothy W. Smith, Karen Weihs (2019) Emotion, social relationships, and physical health: concepts, methods, and evidence for an integrative perspective. Psychosomatic Medicine, 1. 
Wang G., Zhang Y., Zhao J., Zhang J., Jiang F. (2020) Mitigate the effects of home confinement on children during the COVID-19 outbreak. LANCET. Published: March 04.

White, S. H. (2017) Some educated guesses about cognitive development in the pre-school years. In Early Formal Education (pp. 203-214). Routledge.

World Health Organization. Novel Coronavirus-China[EB/OL]. https://www. who.int/csr/don/12-january2020-novel-coronavirus-china/en/,2020-01-30/2020-02-12.

Yi L., Wang Z., Jiang Z., Zheng Y., Wu W. (2010) Research progress of psychological intervention for public health emergencies. Chinese Journal of Public Health, 26(7), 929-930. 